\title{
Formation of Horseradish Peroxidase Compound I with Alkyl
} \section{Hydroperoxides *}

\author{
K. G. PAUL, P. I. OHLSSON and S. WOLD
}

Department of Chemistry, University of Umeå, S-901 87 Umeå, Sweden

The rates of formation of compound I from the acidic isoenzyme horseradish peroxidase A2 and the hydrogen, methyl, ethyl, propyl, butyl, isopropyl, tert-butyl and cumenyl hydroperoxides have been determined. The rate constants, $k_{1}$ app, have been related to other properties of the peroxides: Acidity, dissociation energy of the $\mathrm{RO}-\mathrm{OH}$ bond, rate of diffusion (of the corresponding alcohol ROH), van der Waals volumes and the substituent parameters $\mathrm{MR}, \mathrm{ES}, \pi, \mathrm{L}$ and $\mathrm{B}_{1}$ (molecular refractivity, Taft's steric, Hansch's lipophilic, Verloop's length and width parameters, respectively). A fair correlation was found between $\log k_{1}$ app and $\mathrm{p} K_{\mathrm{a}}$. Steric effects (ES) contribute and account for the difference between the n-alkyl homologues.

Hydroperoxidases are characterized by their high rate of reaction with $\mathrm{H}_{2} \mathrm{O}_{2}$ to form the green compound I.1 Horseradish peroxidase (HRP) ** compound I is also produced by alkyl

* This study was reported at the conference "Frontiers of Biological Energetics: from Electrons to Tissues", University of Pennsylvania, Philadelphia, July 1978 .

** HRP horseradish peroxidase (E.C.1.11.1.7). The Keilin-Theorell-Chance-George mechanism for the action of peroxidases (PO) comprises three

steps:
$\mathrm{Fe}(\mathrm{III}) \mathrm{PO}+\mathrm{ROOH} \stackrel{k_{1} \text { app }}{\longrightarrow}$ compound I+ ROH
Compound I + donor $\stackrel{k_{2}}{\longrightarrow}$ compound II + products
Compound II + donor $\stackrel{k_{3}}{\longrightarrow} \mathrm{Fe}(\mathrm{III}) \mathrm{PO}+$ products

Compound $\mathrm{I}$ is formally pentavalent since it is reduced by two equivalents to the $\mathrm{Fe}$ (III) state. Reaction (1) thus covers several steps. If $k_{1}$ is reserved for the reversible formation of an enzymesubstrate complex reaction (1), the optically operable formation of compound $I$, is assigned the rate constant $k_{1}$ app. and acyl hydroperoxides at somewhat different rates, acylOOH $>\mathrm{HOOH}>$ alkylOOH. ${ }^{2-\infty}$ The rate-limiting function in the formation of compound I may not be identical with all substrate peroxides. A comparison of the rates of the reactions between HRP and various types of hydroperoxides may also be blurred by the occurrence of several effects. Peroxy acids are more reactive than alkyl or aryl hydroperoxides in non-enzymic reactions, ${ }^{7}$ and the corresponding carboxylic acids are better ligands to $\mathrm{Fe}$ (III) HRP than alkohols. The reaction between HRP and $m$-chloroperoxybenzoic acid is diffusionlimited, contrary to the reaction between HRP and $\mathrm{H}_{2} \mathrm{O}_{2}{ }^{8}$ The present attempt to connect the rate of formation of compound $I$ to some property of the hydroperoxide has therefore been confined to studies of alkyl hydroperoxides with the inclusion of one frequently used aryl hydroperoxide. Attempts have also been made to detect any HRP-peroxide compound appearing prior to the formation of compound $I$.

\section{MATERIALS AND METHODS}

The acid isoenzyme HRP A2 (pI 3.9), which gives conveniently operable reaction rates over a wide range, was prepared to give $A_{403} / A_{280} \geq$ 4.15, and homogeneity in disc electrophoresis and isofocussing. Water for buffers etc. was refluxed over $\mathrm{KMnO}_{4}$ and distilled twice, and enzyme solutions were carefully dialyzed before used. The temperature was $25^{\circ} \mathrm{C}$.

Hydroperoxides were either commercially available $\left(\mathrm{H}_{2} \mathrm{O}_{2}\right.$, "Perhydrol 30 \%", Merck, Darmstadt; EtOOH, Ferrosan, Malmö; $t$ BuOOH "zur Synthese", and cumenyl hydroperoxide, Merck-Schuchardt, München) or else synthesized 10,11 and purified by partitions between alkaline buffers and ether/hexane."1 
$\mathrm{H}_{2} \mathrm{O}_{2}$ was standardized against $\mathrm{KMnO}_{1} / \mathrm{di}$ sodium oxalate with confirmation by the HRP catalyzed oxidation of $\mathrm{Fe}$ (II) cytochrome $c$ $\left(\Delta \varepsilon_{550}=19.6 \mathrm{mM}^{-1}\right) .^{12}$ Dicarboxidine $\left(\gamma \gamma^{\prime} \cdot\left(4,4^{\prime}-\right.\right.$ diamino-3,3' -bifenylylenedioxy)dibutyric acid $)^{13}$ reacts with HRP and hydroperoxides in 50 $\mathrm{mM}$ phosphate, pH 6.9, to give a stable, brown product with $\varepsilon_{4 \omega 0}=12.2 \mathrm{mM}^{-1} \mathrm{as}$ determined on the basis of added $\mathrm{H}_{2} \mathrm{O}_{2}$. At $440 \mathrm{~nm}$ HRP and its compounds I and II are nearly isosbestic. This reaction was used for the assay of total hydroperoxide $\left(\mathrm{H}_{2} \mathrm{O}_{2}+\right.$ alkylOOH) in solutions of the alkylhydroperoxides with the exception of tert-butylhydroperoxide. This substance was assayed spectrophotometrically from $\varepsilon_{250}=13 \quad M^{-1} .^{16}$ The concentration of cumenyl hydroperoxide was determined iodimetrically. ${ }^{15}$

Ti(IV) in acid solution reacts instantaneously with $\mathrm{H}_{2} \mathrm{O}_{2}$ to give a yellow colour $\left(\varepsilon_{\mathrm{A} 07}=\right.$ $758 \mathrm{M}^{-1}$ for the reagent used) whereas alkylhydroperoxides react very slowly.10 By means of this reaction the contents of $\mathrm{H}_{2} \mathrm{O}_{2}$ were found in per cent of total hydroperoxide: Methyl 1.6, ethyl 0.9 , propyl and isopropyl 0.6 and butyl $<0.1$. The analyses for contaminating lower peroxides in the tert-butyl and cumenyl hydroperoxides are described together with the results.

$\mathrm{p} K_{\mathrm{a}}$ values of the hydroperoxides were determined optically from $A_{250^{\circ}} A_{\mathrm{ROOH}}$ was measured in sodium borate, $\mathrm{pH} 9.18,{ }^{17}$ and $A_{\mathrm{ROO}^{-}}$in $0.75 \mathrm{M} \mathrm{NaOH}$. Potassium phosphate buffers of pH 11.7-11.9 were used to achieve partial dissociation of the hydroperoxides. pH was determined to the second decimal by means of a Radiometer type B glass electrode, standardized against the borate buffer. $\mathrm{H}_{2} \mathrm{O}_{2}$, assigned $\mathrm{p} K_{\mathrm{a}}=11.60$, was consistently used as a reference. $p K_{\mathrm{a}}$ values were determined in triplicate with S.D. $\pm 0.08 \mathrm{pH}$ units, $n=12$.
Numerical values of $k_{1}$ app were determined by two procedures. (i) The formation of compound I from HRP $(0.5-0.7 \mu \mathrm{M})$ and hydroperoxide in excess was followed at $397 \mathrm{~nm}$. A Durrum-Gibson stopped flow instrument was used for the hydrogen, methyl, ethyl, propyl and butyl hydroperoxides. In competition experiments with two peroxides in this instrument, HRP was mixed at $t=0$ with the slowly reacting peroxide in one syringe, the other syringe containing the rapidly reacting peroxide. Each Durrum-Gibson experiment was run 6-10 times with joint photographic registration, and $12-15$ transmission values from the time range $30-200 \mathrm{~ms}$ were converted to a pseudo first-order rate constant. A Beckman Acta III spectrophotometer was used for the isopropyl and butyl hydroperoxides. (ii) The above direct procedure is inappropriate for very slowly reacting hydroperoxides because of the reduction of compound I by HRP $\mathrm{Fe}(\mathrm{III}) .^{18}$ Dicarboxidine gives stable coloured product(s) and shows a $k_{3}$-value of $6.3 \times$ $10^{5} \mathrm{M}^{-1} \mathrm{~s}^{-1}$ with HRP A2, what makes this donor suitable for the indirect determination of $k_{1}$ app. The expression ${ }^{10}$

$$
\frac{\mathrm{d} x}{\mathrm{~d} t}=\frac{[\mathrm{HRP}]}{\frac{1}{k_{3}[\text { dicarboxidine }]}+\frac{1}{k_{1 \text { app }}[\mathrm{ROOH}]}}
$$

is simplified to

$$
\frac{\mathrm{d} x}{\mathrm{~d} t}=k_{1 \text { app }}[\mathrm{ROOH}][\mathrm{HRP}]
$$

when $\left.k_{3}\right\rangle>k_{1}$ app. This is most likely the case with these peroxides. $\mathrm{d} x / \mathrm{d} t$ is the rate of increase in $A_{440}$ which is proportional to the rate of consumption of $\mathrm{ROOH}$.

Table 1. Rate constants for the formation of compound I from HRP A2 and some hydroperoxides, ROOH. The diffusion coefficients $D$ of the corresponding alcohols ROH are presumed to be

\begin{tabular}{|c|c|c|c|c|c|}
\hline Residue (R) & $\begin{array}{l}k_{1 \text { app }} \\
/ \mathrm{M}^{-1} \mathrm{~g}^{-}\end{array}$ & $\begin{array}{l}\text { No. of } \\
\text { experi- } \\
\text { ments }\end{array}$ & $\begin{array}{l}D_{\mathrm{ROH}^{32}} \\
/ 10^{6} \mathrm{~cm} \mathrm{~s}^{-1}\end{array}$ & $\begin{array}{l}\text { van der } \\
\text { Waals } \\
\text { volume } \\
/ \mathrm{cm}^{3} \mathrm{~mol}^{-1}\end{array}$ & $\mathrm{p} K_{\mathrm{a}}$ \\
\hline $\begin{array}{l}\text { Hydrogen } \\
\text { Methyl } \\
\text { Ethyl } \\
\text { Propyl } \\
\text { Butyl } \\
\text { Isopropyl } \\
\text { tert-Butyl } \\
\text { Cumenyl }\end{array}$ & $\begin{array}{l}2.0( \pm 0.2) \times 10^{8} \\
1.7( \pm 0.1) \times 10^{5} \\
7.6( \pm 0.1) \times 10^{4} \\
3.6( \pm 0.1) \times 10^{4} \\
2.9( \pm 0.2) \times 10^{4} \\
312 \pm 28 \\
4( \pm 2) \times 10^{-2} \\
0.3 \pm 0.1\end{array}$ & $\begin{array}{l}\mathbf{9} \\
\mathbf{3} \\
\mathbf{3} \\
\mathbf{5} \\
\mathbf{1 0} \\
\mathbf{8} \\
\mathbf{5} \\
\mathbf{8}\end{array}$ & $\begin{array}{l}1.70 \\
1.26 \\
1.15 \\
1.00 \\
1.07 \\
0.98\end{array}$ & $\begin{array}{l}3.4 \\
13.7 \\
23.9 \\
34.1 \\
44.4 \\
34.1 \\
44.3 \\
76.5\end{array}$ & $\begin{array}{l}11.6^{34} \\
11.2^{a} \\
11.4^{a b} \\
11.2^{a} \\
11.3^{a} \\
11.7^{a} c \\
12.8^{a} \\
12.6^{8}\end{array}$ \\
\hline
\end{tabular}
proportional to the ROOH coefficients. $10 \mathrm{mM}$ sodium phosphate, $\mathrm{pH} 7.0$.

${ }^{a}$ As titrated optically. ${ }^{b} 11.8 .^{34} c 12.1 .^{34}$ 

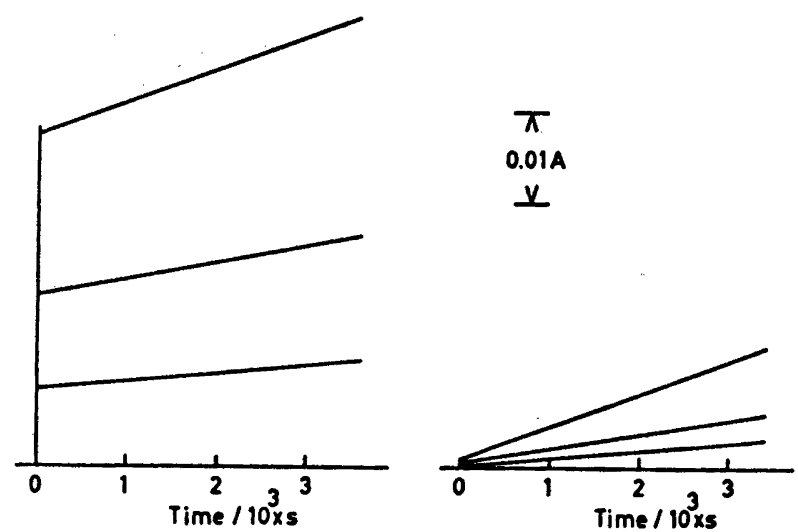

Fig. 1. The biphasic formation of coloured products in the reaction between HRP A2 (2.3 $\mu \mathrm{M})$, dicarboxidine (1.4 mM), and tert-butyl hydroperoxide $(290,570$ and $1120 \mu \mathrm{M}$, corresponding to final absorbancies of 3.5, 7.0 and 13.7). $A_{140}$ increased linearily for $>2.5 \mathrm{~h}$. $a$ Untreated peroxide. $b$ Peroxide treated with catalase + ethanol ( $c$. text). $50 \mathrm{mM}$ sodium phosphate, pH 6.9.

\section{RESULTS}

Reactions with various hydroperoxides. Table 1 collects the second order rate constants for the formation of compound I from HRP A2 and various hydroperoxides and relates them to other properties of the peroxides. The reaction with isopropyl hydroperoxide gave the same numerical value for the rate constant with a 9 and 64-fold excess of peroxide over enzyme.

The addition of tert-butyl hydroperoxide to a solution containing HRP and dicarboxidine caused an immediate (Acta III) increase in $A_{410}$, apparently independent of [HRP] but proportional to the added amount of peroxide
(Fig. 1). It was succeeded by a slow, linear increase in $A_{440}$. The pretreatment of the peroxide $(37 \mathrm{mM})$ with catalase $(20 \mathrm{nM})$ for $18 \mathrm{~h}$ had no effect on this pattern. However, the same pretreatment in the presence of ethanol 20 ( $5 \mathrm{mM}$ ) eliminated $>99 \%$ of the initial, rapid phase, whereas the adjacent slow increase remained unchanged (Fig. 1). This suggests the presence of a small amount of some rapidly reacting peroxide in the tert-butyl hydroperoxide $(0.25$ and $0.5 \%$ of total ROOH in two batches). Because of the lack of effect of catalase alone the contaminant cannot be $\mathrm{H}_{2} \mathrm{O}_{2}$, an interpretation supported by the $\mathrm{Ti}(\mathrm{IV})$ reaction. A direct determination of the rate

Table 2. Rate constant for the formation of compound I from HRP A2 and tert-butyl hydroperoxide, indirectly determined by means of dicarboxidine (1.4 mM). $50 \mathrm{mM}$ sodium phosphate, pH 6.9.

\begin{tabular}{|c|c|c|c|}
\hline $\mathbf{H R P} / \mu \mathrm{M}$ & $\Delta A_{410} / \mathrm{h}$ & $t-\mathrm{Bu} \mathrm{OOH} / \mathrm{mM}$ & $k_{1 \mathrm{app}} / \mathrm{M}^{-1} \mathrm{~s}^{-1}$ \\
\hline $\begin{array}{l}0.7 \\
2.1 \\
2.1 \\
4.2\end{array}$ & $\begin{array}{l}0.0048 \\
0.0113 \\
0.0148 \\
0.0244\end{array}$ & $\begin{array}{l}6.0 \\
6.0 \\
6.0 \\
6.0\end{array}$ & $\begin{array}{l}0.03 \\
0.02 \\
0.03 \\
0.02\end{array}$ \\
\hline $\begin{array}{l}2.4 \\
2.4 \\
2.3 \\
2.3 \\
2.2\end{array}$ & $\begin{array}{l}0.0023 \\
0.0020 \\
0.0018 \\
0.0078 \\
0.0055\end{array}$ & $\begin{array}{l}0.23 \\
0.40 \\
0.57 \\
1.12 \\
2.72\end{array}$ & $\begin{array}{l}0.08 \\
0.05 \\
0.03 \\
0.07 \\
0.02\end{array}$ \\
\hline & & Average \pm S.D. & $0.04 \pm 0.02$ \\
\hline
\end{tabular}

Acta Chem. Scand. B 33 (1979) No. 10 
Table 3. Rate constant for the formation of compound I from HRP A2 and cumenyl hydroperoxide. Indirect determination by means of dicarboxidine $(1.2 \mathrm{mM}) .50 \mathrm{mM}$ sodium phosphate, $\mathrm{pH} 6.9$.

\begin{tabular}{llll}
\hline $\mathrm{HRP} / \mu \mathrm{M}$ & Cumenyl $\mathrm{OOH} / \mu \mathrm{M}$ & $\Delta A_{440} / \mathrm{h}$ & $k_{1 \mathrm{app}} / \mathrm{M}^{-1} \mathrm{~s}^{-1}$ \\
\hline & & & \\
3.5 & 317 & 0.0072 & 0.34 \\
5.9 & 627 & 0.0120 & 0.15 \\
3.0 & 1243 & 0.0438 & 0.14 \\
3.0 & 2045 & 0.0165 & 0.10 \\
& & 0.0368 & 0.14 \\
& & Average & $0.17 \pm 0.09$ \\
\hline
\end{tabular}

constant of the rapid phase gave a value of $k_{1 \text { app }} \cong 10^{5} \mathbf{M}^{-1} \mathrm{~s}^{-1}$. This order of magnitude together with the effect of catalase + ethanol identifies the contaminant as a short-chained alkyl hydroperoxide. So pretreated tert-butyl hydroperoxide was used for the determination of $k_{1}$ app. Table 2 shows that the rate of increase in $A_{\text {uto }}$ was proportional to [HRP] and [peroxide], i.e. the reaction is of second order.

The purified cumenyl hydroperoxide produced a similar biphasic increase in $A_{440}$ during the dicarboxidine reaction. The immediate increase corresponded to a content of $0.05 \%$ of rapidly reacting peroxide. The slope of the adjacent, linear increase was proportional to the enzyme and peroxide concentrations (Table 3) with a rate constant of $0.17 \mathrm{M}^{-1} \mathrm{~s}^{-1}$.

Effect of increased solvent viscosity. The velocity of the reaction between HRP A2 and isopropyl hydroperoxide was identical in buffer $\left(k_{1 \text { app }}=312 \pm 28, n=8\right)$ and in buffer containing $1.16 \mathrm{M}$ sucrose $\left(k_{1 \mathrm{app}}=313 \pm 26, n=5\right)$. This sucrose concentration gives a 3 -fold increase in viscosity. ${ }^{8}$

Additional searches for an HRP-peroxide complex. The reactions between HRP A2 and various hydroperoxides to form compound I are of second order, and no saturation kinetics were found. As independent searches for an enzyme-substrate complex the rates of the reaction between HRP A2 and isopropyl hydroperoxide were compared at $397 \mathrm{~nm}$ (change in the Soret band) and $240 \mathrm{~nm}$ (possible change in absorbance due to the peroxide). The two wavelengths gave, however, identical $k_{1}$ app-values, and there was no change in $A_{240}$ prior to the formation of compound $I$.
Admittedly, the negative result may depend upon insufficient resolution of the DurrumGibson instrument.

When HRP A2 and isopropyl hydroperoxide were mixed in one syringe of the stopped flow apparatus the slow formation of compound I

$$
\begin{aligned}
& \text { Time after mixing } / \min _{\text {HRP A2 and } \mathrm{i}-\mathrm{PrOOH}} \quad 10^{-6} \times \mathrm{k}_{1, \mathrm{app}} / \mathrm{M} \times \mathrm{s} \\
&
\end{aligned}
$$

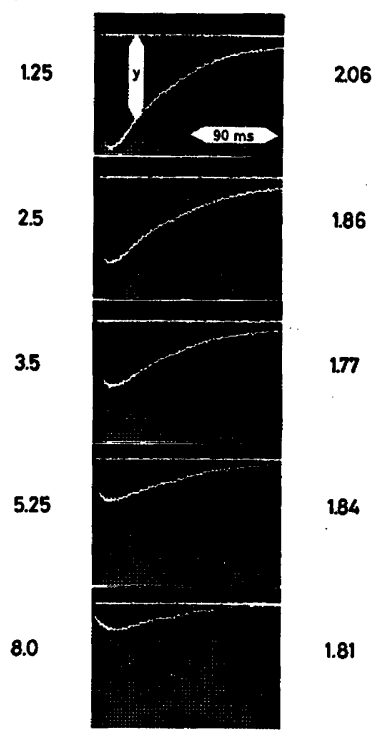

Fig. 2. Formation of compound I from HRP A2 and $\mathrm{H}_{2} \mathrm{O}_{2}$ at various times after mixing HRP A2 and isopropyl hydroperoxide. Deflection upwards means increasing transmittance (397 $\mathrm{nm}$ ). Syringe 1: $1.4 \mu \mathrm{M}$ HRP A2, 12.0 $\mu \mathrm{M}$ isopropyl hydroperoxide. Syringe 2: $15.4 \mu \mathrm{M}$ $\mathrm{H}_{2} \mathrm{O}_{2}$. " $\mathrm{y}$ " to be used in Fig. 3 is measured in $\mathrm{mm}$ at a constant time $(\mathbf{4 3} \mathrm{ms})$ after mixing HRP and $\mathrm{H}_{2} \mathrm{O}_{2} .10 \mathrm{mM}$ sodium phosphate, pH 7.0. 


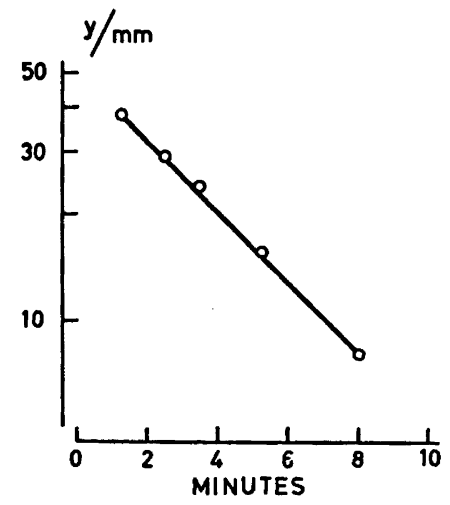

Fig. 3. Rate of formation of compound I from HRP A2 and isopropyl hydroperoxide. Ordinate: "y" as defined in Fig. 2, approximately proportional to [free HRP]. Abscissa: Time after mixing HRP A2 and isopropyl hydroperoxide in syringe 1 .

began, leaving less and less unchanged HRP to react with $\mathrm{H}_{2} \mathrm{O}_{2}$ from syringe 2. The decrease in free HRP (Figs. 2 and 3) gave a rate constant for the reaction between HRP and isopropyl hydroperoxide $\left(340 \mathrm{M}^{-1} \mathrm{~s}^{-1}\right)$ equal to that found by mixing HRP A2 and this peroxide in an open cuvette (Table 1). HRP A2 in syringe 1, which had been exposed to isopropyl hydroperoxide for several minutes, but not yet been converted to compound $I$, reacted with $\mathrm{H}_{2} \mathrm{O}_{2}$ at a constant rate $\left(1.9( \pm 0.1) \times 10^{6} \mathrm{M}^{-1} \mathrm{~s}^{-1}\right)$, equal to that obtained from the experiments with HRP A2 and $\mathrm{H}_{2} \mathrm{O}_{2}$ alone (Table 1).

\section{DISCUSSION}

The reactions between HRP and the hydrogen, methyl and ethyl hydroperoxides to form compound I are known to be second order. ${ }^{1,21}$ The present results show that also the reactions with the isopropyl, tert-butyl and cumenyl hydroperoxide are of this order.* No sign of saturation kinetics was detected at $\mathrm{pH} \mathrm{7,} \mathrm{in} \mathrm{agreement} \mathrm{with} \mathrm{recent} \mathrm{results} \mathrm{with}$ $\mathrm{H}_{2} \mathrm{O}_{2}$ by Dunford et al..$^{22}$ At $\mathrm{pH}>10$, however,

* Two reviews ${ }^{36,37}$ mention that HRP and tertbutyl hydroperoxide do not react, but we have been unable to identify the ultimate source of this information. We thank Drs. Arthur S. Brill and Philip George for kind assistance in these attempts. these authors demonstrated saturation kinetics in the formation of compound I from HRP and $\mathrm{H}_{2} \mathrm{O}_{2}$, which strongly indicates the formation of an enzyme-substrate complex. Our attempts failed to reveal the existence of a peroxide-peroxidase complex prior to the appearance of compound I. The inability of isopropyl hydroperoxide to inhibit the reaction with $\mathrm{H}_{2} \mathrm{O}_{2}$ as well as the second order kinetics is compatible with the formation of a weak peroxidase-peroxide complex with a forward rate of decomposition that limits the overall velocity.

The velocity of the reaction between HRP A2 and various alkyl hydroperoxides spans over a wide range, from $k_{1}$ app $=2 \times 10^{8}$ to $4 \times 10^{-2} \mathrm{M}^{-1} \mathrm{~s}^{-1}$ (Table 1). A plot of $\log k_{1 \text { app }}$ against the other logarithmic function $\mathrm{p} K_{\mathrm{a}}$ shows a linear, negative slope, not parallel to the $y$-axis $(t>11)$ (Fig. 4). This conveys the impression that the acidity of the hydroperoxide profoundly influences the rate of formation of compound I. It may signify a cause and effect situation or reveal a simple covariation. The latter situation would arise if $K_{\mathrm{a}}$ and $k_{1}$ app both were influenced by some common property of the peroxide molecule, responding to substitution in the alkyl group. The four n-alkyl hydroperoxides were found to have essentially the same $p K_{\mathrm{a}}$ values, and the significant albeit small differences in their $k_{1}$ app values reveal the existence of one or several effects, modifying that of the acidity.

The $\mathrm{RO}-\mathrm{OH}$ dissociation energy is a candidate, since compound $I$ carries one $O$ from $\mathrm{ROOH}$. Actual values are $180-184 \mathrm{~kJ} \times$ $\mathrm{mol}^{-1}$ for $\mathrm{R}=\mathrm{CH}_{3}, \mathrm{C}_{2} \mathrm{H}_{5}$, iso $-\mathrm{C}_{3} \mathrm{H}_{7}$ and tert $-\mathrm{C}_{4} \mathrm{H}_{2}$ and higher for $\mathrm{H}_{2} \mathrm{O}_{2}\left(213 \mathrm{~kJ} \mathrm{~mol}{ }^{-1}\right){ }^{23}$ Hence this property cannot cause the variation in

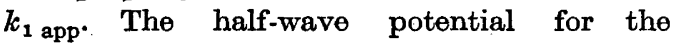
polarographic reduction of peroxide to alcohol is somewhat better correlated to $k_{1}$ app but still much inferior to $p k_{\mathrm{a}}$ in this respect. ${ }^{24}$

Provided that the diffusion coefficients of the alcohols in Table 1 reflect the diffusion coefficients of the corresponding peroxides methyl hydroperoxide diffuses about twice as fast as tert-butyl hydroperoxide whereas the rate constants give a ratio $>10^{8}$. The reaction between HRP A2 and isopropyl hydroperoxide is not hampered by increased viscosity. Diffusion seems not to be rate limiting in the

Acta Chem. Scand. B 33 (1979) No. 10 

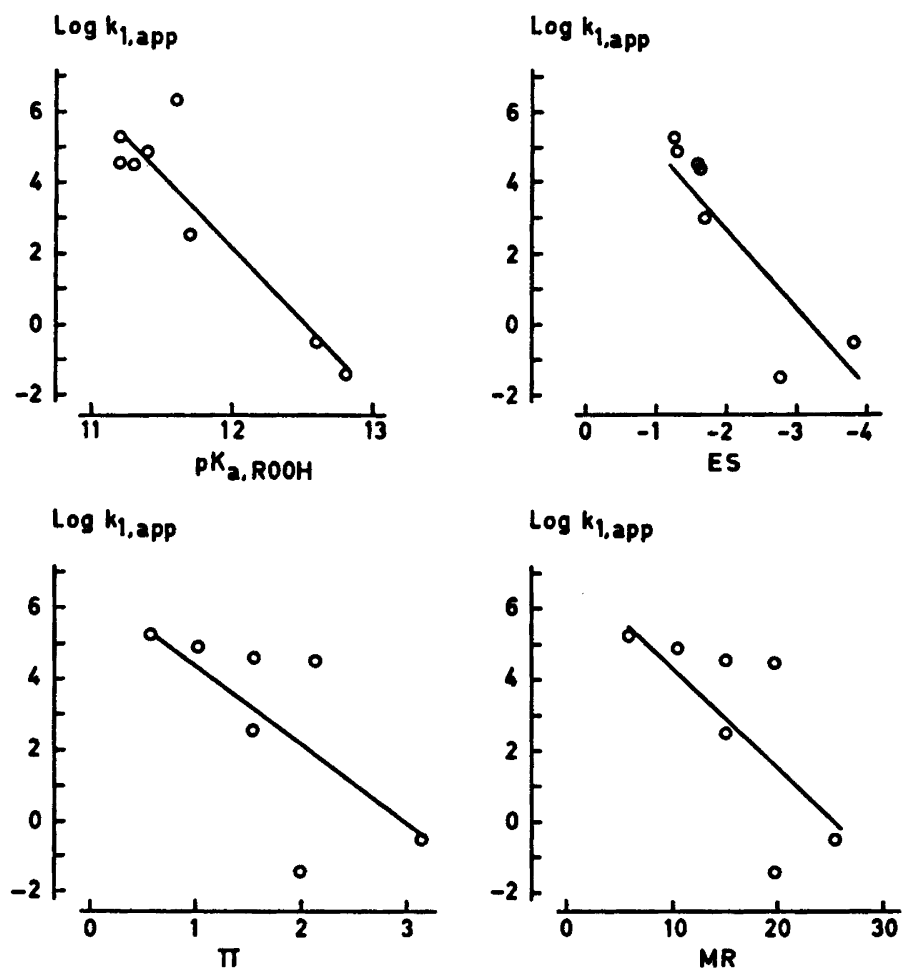

Fig. 4. Correlations between rate constants for the formation of HRP A2 compound I with various peroxides $\left(k_{1}\right.$ app $)$ and four parameters, expressing different properties of the hydroperoxide molecule (cf. text). The rate constants refer to $\mathbf{R O O H}$ with $\mathbf{R}$ (from top) $=\mathbf{H}$, methyl, ethyl, propyl, butyl, isopropyl, cumenyl and tert-butyl.

reactions with alkyl hydroperoxides. Interestingly, Fig. 4 predicts that an arylacyl hydroperoxide with a low $\mathrm{pK}_{\mathrm{a}}$ should react even more rapidly than $\mathrm{H}_{2} \mathrm{O}_{2}$, as actually found;" a first ceiling is set by diffusion-limitation. ${ }^{8}$ A review ${ }^{25}$ of the formation of catalase compound I with various hydroperoxides concluded, by rejecting alternatives, that van der Waals volume was the rate-determining parameter. The rate constant for HRP A2 is somewhat correlated to this property although less than to $\mathrm{p} K_{\mathrm{a}}$ ( $r=0.788$ for $\log k_{1}$ and van der Waals volume). The ratios of the $k_{1}$ app values with the two $C_{3}$ and even more with the two C. peroxides show, however, that van der Waals volume itself is not decisive. A resolution of van der Waals volume into the quantum mechanically deduced parameters Verloop's L (length) and $B_{1}$ (width) ${ }^{26}$ gives the correlation coefficients -0.439 and -0.837 , respectively, which confirms the small contribution of van der Waals volume per se.

A plot of $\log k_{1}$ app against the molecular weight the alkyl group separates to some extent the straight- and branched-chained peroxides, suggesting steric effects. Independent analyses of contributary effects can be made by means of Taft's parameter ES for steric effects ${ }^{27}$ and Hansch's parameter $\pi$ for lipophilicity. ${ }^{28}$ The latter is preferred to the closely related polarizability index $\mathrm{MR} *$ since the distribution of the hydroperoxide between the bulk water and a less polar binding site has been considered as influencing $k_{1 \text { app }} .4$ The parameters $\mathrm{p} K_{\mathrm{a}}, \mathrm{ES}$, and $\pi$ are basically related although they emphasize different properties of the peroxide. Fig. 4 shows that

* Pomona College Medicinal Chemiatry Data Bank. $\log k_{1}$ app ve. MR gives $r=0.780$.

Acta Chem. Scand. B 33 (1979) No. 10 
Table 4. Statistical analysis of models $1-3$ (eqns. 6-8).

\begin{tabular}{|c|c|c|c|c|c|}
\hline Model (eqn.) & $\begin{array}{l}\text { Multiple corre- } \\
\text { lation coeff. }\end{array}$ & $\begin{array}{l}\text { Residual stand- } \\
\text { ard deviation }\end{array}$ & $a$ & $b$ & $c$ \\
\hline $\begin{array}{l}1(6) \\
2(7) \\
3\left(X=\mathrm{p} K_{\mathrm{a}}\right)(8) \\
3(X=\mathrm{ES})(8) \\
3(X=\pi)(8) \\
2(7)^{a} \\
3\left(X=\mathrm{p} K_{\mathrm{a}}\right)(8)^{a}\end{array}$ & $\begin{array}{l}0.965 \\
0.976 \\
0.92 \\
0.90 \\
0.77 \\
0.989 \\
0.989\end{array}$ & $\begin{array}{l}0.87 \\
0.73 \\
1.18 \\
1.34 \\
1.95 \\
0.49 \\
0.44\end{array}$ & $\begin{array}{r}42.5 \\
35.3 \\
51.7 \\
7.2 \\
6.5 \\
\mathbf{4 8 . 2} \\
\mathbf{4 9 . 8}\end{array}$ & $\begin{array}{r}-3.2 \\
-2.6 \\
-4.1 \\
2.2 \\
-2.2 \\
-3.8 \\
-4.0\end{array}$ & $\begin{array}{r}-1.0 \\
1.2\end{array}$ \\
\hline
\end{tabular}

a $\mathrm{H}_{2} \mathrm{O}_{2}$ omitted.

both ES and $\pi$ describe to some extent, but less so than $\mathrm{p} K_{\mathrm{a}}$, the effects of the substitutions of $R$ on $\log k_{1}$ app. In the simplest case this would be quantified by the model

$\log k_{1 \mathrm{app}}=a+b \times \mathrm{p} K_{\mathrm{a}}+c \pi+\varepsilon$

or

$\log k_{1 \mathrm{app}}=a+b \times \mathrm{p} K_{\mathrm{a}}+c \mathrm{ES}+\varepsilon$

where $\varepsilon$ is the residual, i.e. the difference between the observed and calculated values. Multiple regression analyses of these two models gave the results in Table 4. Results for the simpler model

$\log k_{1 \mathrm{app}}=a+b X+\varepsilon$

with $X=\mathrm{p} K_{\mathrm{a}}, \pi$, or ES are given for comparison. Eqn. (7) gives a slightly better fit than eqn. (6), both being preferable to the simpler model. Fig. 4 shows that $\mathrm{p} K_{\mathrm{a}}$ gives a better fit than ES at low velocities whereas the situation is reversed at high velocities. As regards the effect of $\mathrm{p} K_{\mathrm{a}}$ the four n-alkyl peroxides can be considered essentially a single substrate. The value $\mathrm{p} K_{\mathrm{a}}=11.6$ for $\mathrm{H}_{2} \mathrm{O}_{2}$ is used as obtained. The symmetry effect in $\mathrm{H}_{2} \mathrm{O}_{2}$ and the difference between $\mathbf{R}=\mathbf{H}$ and $\mathrm{R}=$ alkyl give $\mathrm{H}_{2} \mathrm{O}_{2}$ an outlying position, and the result with this substrate could therefore even be excluded from the statistical treatment. Table 4 includes this alternative, in which $\mathrm{p} K_{\mathrm{a}}$ is quite dominating. Since the parameters ES, $\pi$ and MR are not available for $R=$ cumenyl the values for phenyl have been used. The correct cumenyl values would further increase the standard deviations for these parameters. Even this correction would increase the relative importance of $\mathrm{p} K_{\mathrm{a}}$.

Acta Chem. Scand. B 33 (1979) No. 10
The replacement of a methyl group in tertbutyl hydroperoxide by a phenyl group yields cumenyl hydroperoxide, which thus bears some resemblance to the arylacyl hydroperoxides. Its reaction rate fits into the pattern given by the $\mathrm{p} K_{\mathrm{a}}$ values of the alkyl hydroperoxides in Fig. 4, which denies the aromatic structure a major role as a functional ligand in the formation of compound $I$.

The acidity of the hydroperoxide seems to be the parameter that dominates the rate of formation of HRP A2 compound I with alkyl hydroperoxides. Some contribution is given by steric factors and, to a lesser extent, lipophilicity. The correlation is such that a given change in $K_{\mathrm{a}}$ is magnified nearly $10^{\circ}$-fold in $k_{1}$ app. Mechanistically, this amplification can be attributed to manifestations in two different environments of the same property of the alkyl hydroperoxide, the ability to release its hydrogen. The macroscopic equilibrium constant $K_{\mathrm{a}}$ expresses a charge separation in aqueous solution, whereas $k_{1}$ is related to a process in a less polar microstructure.

HRP accepts a protonated acid but utilizes the conjugate base as a ligand..$^{21,4,20} \mathrm{~A}$ peroxy anion in the bulk medium is not a reactant in the peroxidase mechanism. This fact has generated a model with a negatively charged electrostatic gate outside the active site." Gates are known to have steric effects, and the model might hence account also for a ratelimiting contribution from the size of the substrate. Once inside, the hydroperoxide has to dispose of its proton. A mechanism for this disposal is offered by the observation of a hydrogen bond between $\mathrm{CO}$ and a protonated 
protein group in $\mathrm{Fe}$ (II)COHRP..$^{30}$ Here the protein supplies a proton acceptor at a suitable distance from the iron atom. A chemical modification of this protein group prevents the formation of the $\mathrm{FeCO} \cdots \mathrm{H}$ - protein bond and also the formation of compound $I .^{31}$

In summary the following picture emerges. Ionization of a hydroperoxide creates an absolute obstacle to the passage through an electrostatic gate in the peroxidase." Steric factors somewhat hamper the entrance of an alkyl hydroperoxide. The proton-detaching inside the gate becomes the major rate-limiting step in the reaction with alkyl hydroperoxides but not so with the stronger acids arylacyl hydroperoxides. Instead, their approach to the enzyme molecule through the medium is limiting, ${ }^{8}$ which does not imply very different diffusion rates for alkyl and arylacyl hydroperoxides.

Acknowledgements. This work was supported in part by the Swedish Medical Research Council (13X-4267). A travelling grant (K.G.P.) from the University of Umea is gratefully acknowledged. Mrs. U.-B. Mattsson expertly typed the manuscript. Dr. A. Jönsson, KABI, Stockholm, kindly supplied a sample of dicarboxidine.

\section{REFERENCES}

1. Chance, B. Arch. Biochem. Biophys. 22 (1949) 224; 24 (1949) 410.

2. Cotton, M. L. and Dunford, H. B. Can. J. Chem. 51 (1973) 582.

3. Marklund, S., Ohlsson, P. I., Opara, A. and Paul, K. G. Biochim. Biophys. Acta 350 (1974) 304.

4. Davies, D. R., Jones, P. and Mantle, D. Biochem. J. 157 (1976) 247.

5. Schonbaum, G. R. and Lo, S. J. Biol. Chem. 247 (1972) 3353.

6. Job, D. and Jones, P. Eur. J. Biochem. 86 (1978) 565.

7. Mair, R. D. and Hall, R. T. In Swern, D., Ed., Organic Peroxides, Wiley, New York 1971, Vol. 2, p. 538.

8. Dunford, H. B. and Hewson, W. D. Biochemistry 16 (1977) 2949.

9. Paul, K. G. and Stigbrand, T. Acta Chem. Scand. 24 (1970) 3607.

10. Criegee, R. In Houben-Weil, Methoden der organischen Chemie, 4th Ed., Thieme, Stuttgart 1952, Vol. 8, p. 34.

11. Williams, H. R. and Mosher, H. S. J. Am. Chem. Soc. 76 (1954) 2984, 2987.

12. Yonetani, T. J. Biol. Chem. 240 (1965) 4509.
13. Jönsson, A., Merenyi, F., Svahn, D. M. and Gyllander, J. Acta Chem. Scand. B 32 (1978) 317.

14. Battaglia, C. J. Thesis, Brown University, Brown 1962; Quoted from Swern, D., Ed., Organic Peroxides, Wiley, New York 1971, Vol. 1, p. 209.

15. Kokatnur, V. R. and Jelling, M. J. Am. Chem. Soc. 63 (1941) 1432.

16. Marklund, S. Acta Chem. Scand. 25 (1971) 3517.

17. Bates, R. G. Determination of $p H$, Wiley, New York 1973.

18. Santimone, M. Biochimie 57 (1975) 265.

19. Chance, B. and Maehly, A. C. Methods Enzymol. 2 (1955) 764.

20. Keilin, D. and Hartree, E. F. Biochem. J. 39 (1945) 293.

21. Chance, B. Adv. Enzymol. 12 (1951) 153.

22. Job, D. and Dunford, H. B. Can. J. Chem. 56 (1978) 1327.

23. Hiatt, R. In Swern, D., Ed., Organic Peroxides, Wiley, New York 1971, Vol. 2, p. 46.

24. Silbert, L. S. In Swern, D., Ed., Organic Peroxides, Wiley, New York 1971, Vol. 2, p. 768.

25. Schonbaum, G. R. and Chance, B. In Boyer, P. D., Ed., The Enzymes, 3rd Ed., Academic, New York 1976, Vol. 13, Chapter 7.

26. Verloop, A., Hoogenstraten, W. and Tipker, J. In Ariens, E. J., Ed., Drug Design, Academic, New York 1971, Vol. 5.

27. Taft. R. W. In Newman, M. S., Ed., Steric Effects in Organic Chemistry, Wiley, New York 1956, p. 556.

28. Hansch, C., Leo, A., Unger, S. H., Kim, K. H., Nikiatani, D. and Lien, E. J. J. Med. Chem. 16 (1973) 1207.

29. Jones, P. and Dunford, H. B. J. Theoret. Biol. 69 (1977) 457.

30. Barlow, C. H., Ohlsson, P. I. and Paul, K. G. Biochemistry 15 (1976) 2225.

31. Schonbaum, G. R., Houtchens, R. A. and Caughey, W. S. Poster at the conference Frontiers of Biological Energetics: from Electrons to Tissues, Philadelphia 1978.

32. Gary-Bobo, C. and Weber, H. W. J. Phys. Chem. 73 (1969) 1155.

33. Bondi, A. J. Phys. Chem. 68 (1964) 441.

34. Everett, A. J. and Minkoff, G. J. Trans. Faraday Soc. 49 (1953) 410.

35. Kolthoff, I. M. and Medalia, S. J. J. Am. Chem. Soc. 71 (1949) 3789.

36. Dunford, H. B. and Stillman, J. S. Coord. Chem. Rev. 19 (1976) 187.

37. Brill, A. S. In Florkin, M. and Stolz, E. H., Eds., Comprehensive Biochemistry 14 (1966) 447.

Received June 20, 1979.

Acta Chem. Seand. B 33 (1979) No. 10 